\title{
PSEUDOPODIAL INTERDIGITATIONS BETWEEN ABUTTED NERVE TERMINALS: DIFFUSION TRAPS WHICH OCCUR IN SEVERAL NUCLEI OF THE RAT LIMBIC SYSTEM ${ }^{1}$
}

\author{
ALAN F. BOYNE ${ }^{*, 2}$ AND SALLY B. TARRANT $\ddagger$ \\ * Department of Pharmacology and Experimental Therapeutics, University of Maryland School of Medicine, Baltimore, \\ Maryland 21201 and $\$$ Department of Pharmacology, Northwestern Medical School, Chicago, Illinois 60611
}

Received March 25, 1981; Revised October 26, 1981; Accepted November 25, 1981

\begin{abstract}
Stimulation of the Torpedine ray electric organ can cause the loss of synaptic vesicles and the growth of pseudopodia from the nerve terminals (Boyne, A. F., and S. McLeod (1979) Neuroscience 4: 615-624). The latter embed themselves in corresponding indentations in abutted terminals. The geometry of these pseudopodial indentations (PSIs) can vary: (i) in length, (ii) in the extent of constriction of the base, and (iii) through a compound interaction between different pseudopodia extending in opposite directions.

Examination of six rat brain nuclei in the limbic system has shown that their neuropil can be categorized according to the prevalence of either (i) nerve terminals indented by nerve terminal outgrowths (i.e., PSIs) or (ii) nerve terminals indented by dendritic outgrowths: these have been previously termed spinules. Clusters of simple PSIs were seen in the central nucleus of the amygdala, while base-constricted and compound forms were found in the globus pallidus and substantia nigra. Dendritic spinules were prevalent in the nucleus accumbens and the molecular layer of the hippocampus. In the $\mathrm{CA}_{4}$ hilar region of the hippocampus, large nerve terminals containing PSIs were found. The caudate neuropil appeared to be of mixed character in that the small terminals often had spinules but occasionally showed PSIs.

Spinules have been recognized for many years and the possibility of their plasticity has been raised previously (Tarrant, S. B., and A. Routtenberg (1977) Tissue Cell 9: 461-473). The present report appears to be the first detailed description of an alternative form of invasion which is known to be plastic in the elasmobranch electric organ. It is suggested that the extracellular space between the partners of a PSI could act as variable diffusion traps. If the involved boutons carry action potentials, then nonsynaptic release and accumulation of substances such as potassium, amino acids, and nucleotides may be expected during stimulation. Consequent direct or receptor-mediated effects on the membrane potential could influence transmission through adjacent synapses.
\end{abstract}

In several peripheral nervous system preparations, it has been shown that neurosecretion can be activated at rates which result in net exocytotic loss of synaptic vesicles (Ceccarelli et al., 1973; Heuser and Reese, 1973; Pysh and Wiley, 1974; Zimmermann and Whittaker, 1974; Boyne et al., 1975). Under these conditions, nerve terminals must change their shape in order to accommodate

\footnotetext{
${ }^{1}$ This work was supported by National Institute of Neurological and Communicative Disorders and Stroke Grants NS13043 and NS16167. A. B. wishes to thank Dr. Ulf Karlsson, whose teaching encouraged the decision to undertake the study and Drs. Daniel Weinreich and James Houk for valuable discussions.

${ }^{2}$ To whom correspondence should be addressed at Department of Pharmacology and Experimental Therapeutics, University of Maryland School of Medicine, $660 \mathrm{~W}$. Redwood Street, Baltimore, MD 21201.
}

an increased surface area to volume ratio. Geometric changes also have been reported in central preparations, e.g., stimulated afferents to the hatchetfish Mauthner cell (Model et al., 1975), bullfrog retina during darkness (Schaeffer and Raviola, 1978), and in stimulated nerve terminals of lamprey spinal cord (Kershaw and Christensen, 1980).

In the electric organ of the Torpedine ray, Narcine brasiliensis, the response involved the formation of nerve terminal pseudopodia (Boyne et al., 1975). A cooperative interaction occurs in which an adjacent, directly abutted terminal forms a matching indentation so that both undergo a similar increase in surface area. Three-dimensional reconstructions show that the pseudopodial indentations (PSIs) reach lengths of $3 \mu \mathrm{m}$ and that two basic configurations occur (Boyne and McLeod, 1979). The 
simplest form is illustrated diagrammatically in Figure $1 A$. In addition, a "compound" arrangement occurs when a terminal with an outgoing pseudopodium is indented by another coming from the adjacent nerve terminal (Fig. 1B); the length of the apposed membranes is thereby increased. Finally, the reconstructions showed that PSIs could be constricted and apparently detached at the base.

In order to approach the question of whether similar apparently exocytotically driven geometric changes could influence information processing in the CNS, we have first asked whether abutted nerve terminals in the rat brain show any tendency to form PSIs. Although they do not appear to have been described in standard reference works on the ultrastructure of the brain, we have found that they are widespread. This paper describes their various forms and distributions among rat limbic system nuclei. Our preliminary report on their presence
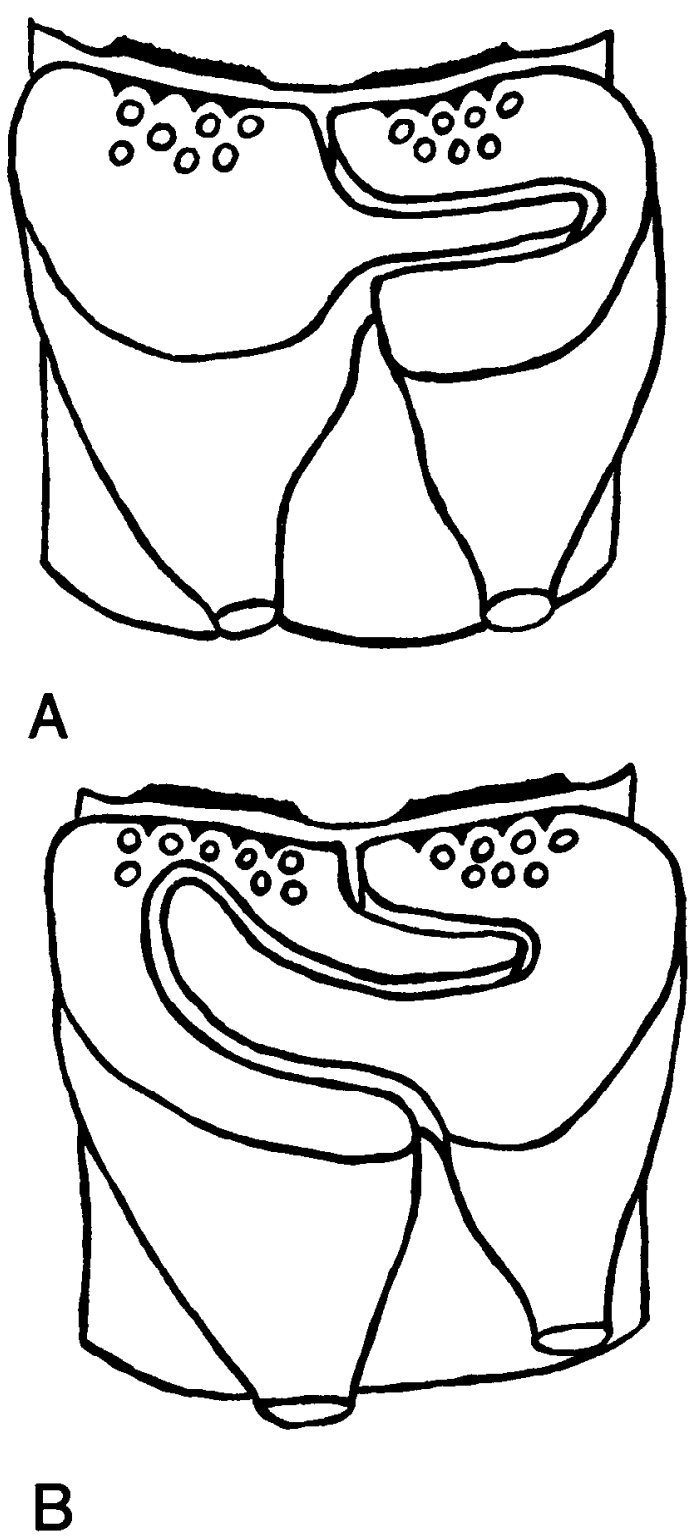

Figure 1. Diagrams of the inter-relationship developing between abutted nerve terminals in stimulated Narcine brasiliensis electric organ. $A$, Simple form; $B$, compound form. in the amygdala (Boyne and Tarrant, 1979) coincided with a report that they occur in the monkey globus pallidus (DiFiglia et al., 1979). Furthermore, an earlier paper on the monkey globus pallidus by Fox et al. (1974) had described "dovetailed" nerve terminals around the smooth dendrites. The accompanying micrographs showed clear PSIs in both longitudinal and cross-sections. This information led us to examine the rat globus pallidus. In addition, we have surveyed the rat hippocampus $\left(\mathrm{CA}_{1}\right.$ and $\mathrm{CA}_{4}$ regions), nucleus accumbens, caudate, and substantia nigra.

How might the presence of these structures influence synaptic transmission? One possibility is that the blindended extracellular cavity would be a diffusion trap. A variety of substances are known to be released nonsynaptically from stimulated unmyelinated nerves, e.g. potassium (see reviews by Somjen, 1979; Orkand, 1980; Nicholson, 1980) and glutamate (Weinreich and Hammerschlag, 1975). There is also a possibility of nucleotide release from depolarized membranes (Abood et al., 1962). Such compounds may be expected to be released from the closely apposed neural membranes of a PSI during an action potential. The concentrations attained could be substantial because (i) the extracellular volume is very small, (ii) both membranes could release solutes, and (iii) diffusional escape can occur only at one end.

\section{Materials and Methods}

Male, Sprague-Dawley rats were obtained from Charles River Laboratories. They were anesthetized with sodium pentobarbital or urethane and were perfused sequentially through the heart with $250 \mathrm{ml}$ of dilute Karnovsky (1965) fixative at $40 \mathrm{ml} \mathrm{min}{ }^{-1}$ and $37^{\circ} \mathrm{C}$ followed by $250 \mathrm{ml}$ of concentrated fixative at room temperature and at a gradually reduced rate of flow. The initial studies were done with $5 \mathrm{~mm} \mathrm{CaCl} 2$ in a cacodylate buffer as suggested by Karnovsky (1965); we later switched to $5 \mathrm{mM} \mathrm{CoCl} 2$ with the intention of suppressing synaptic transmission during perfusion (after Birks, 1974; Chang et al., 1979). After a total perfusion time of about $20 \mathrm{~min}$, the rats were decapitated and the skull was split open. Only well perfused brains were processed further. They were mounted on a Vibratome (Pella, Inc., Tustin, CA 92680) and 2- to $300-\mu \mathrm{m}$ sections were taken until the regions of interest could be clearly identified using the atlas of Konig and Klippel (1970). The intended nuclei were cut out and postfixed. The initial studies included en bloc staining with uranyl maleate in an attempt to increase membrane contrast, but this proved unnecessary when Karnovsky's (1971) postfixation in 1\% osmium tetroxide and $1.5 \%$ potassium ferrocyanide was used.

\section{Results}

\section{Ultrastructural studies}

Brain areas were examined in the following chronological sequence.

Central nucleus of the amygdala. Several of the ultrastructural features of the amygdaloid nuclei of the cat described by Hall (1968) were also apparent in the rat central nucleus. Of particular importance for the present study, portions of the smooth, spine-free dendrites were 
completely lined with abutted synaptic boutons. With diligent searching, what appeared to be pseudopodial profiles cut in longitudinal and in cross-section could be identified within nerve terminals making axodendritic synapses onto large ( $\sim 4-\mu$ m-diameter) dendrites. A definitive demonstration that these structures are analogous to those seen in stimulated electric organ required that their terminations and origins be located. Although the frequency of occurrence is low, we formed the impression from single sections that the presence of one example increased the likelihood of seeing more in the same region. After scanning a large block face, we therefore located a region with several pseudopodia and reduced the size of the block face for serial sectioning. Sections of a 5- $\mu \mathrm{m}$ length of the relevant dendrite were prepared and photographed. Since it had an elliptical profile, it was possible to draw the widest diagonal across it in successive prints and to reconstruct the third dimension graphically as described previously (Boyne and McLeod, 1979). The appearances of the two sides of the dendrite are shown in Figure 2.

It can be seen from the drawing that the apparent pseudopodial invasion visible at the top of Figure 2 is, in fact, a fold when the third dimension is revealed. Similar forms were observed in stimulated electric organ. In the present case, it appears to have been an accurate predictor of more characteristic pseudopodia further along the dendrite. Figure 3 shows a particularly fortunate config- uration of a longitudinally cut PSI base alongside a second cross-sectioned PSI within the same terminal. The arrow in Figure $2 A$ shows the level at which this occurred in the dendritic reconstruction.

A curious feature of the reconstruction was that six pseudopodia plus two folds were present in 11 boutons on one side, while no such structures were apparent in 11 boutons on the other side. The latter was the surface closest to the cell soma up to which the dendrite was traced. Terminals bearing PSIs were found to make symmetrical synapses with the dendrite and to possess a mixed complement of round and flattened, clear synaptic vesicles together with a scattering of dense core vesicles. These characteristics were not adequate to distinguish $a$ priori such terminals from the many others which did not appear to form PSIs.

No synaptic or other membrane specializations were observed in any of the serial sections on either the invading or the invaginating membrane. The packing density of synaptic vesicles within PSIs was generally lower than that alongside synaptic densities.

The lengths of the apparent diffusion paths along the six pseudopodial forms reconstructed were $0.6,0.6,0.8$, $0.8,1.0$, and $1.8 \mu \mathrm{m}$ (Fig. 2).

Hippocampus. The $\mathrm{CA}_{1}$ region was examined from stratum oriens down to the granule cell layer. The bulk of the neuropil is occupied by small nerve terminals articulating with dendritic spines. In the molecular layer,
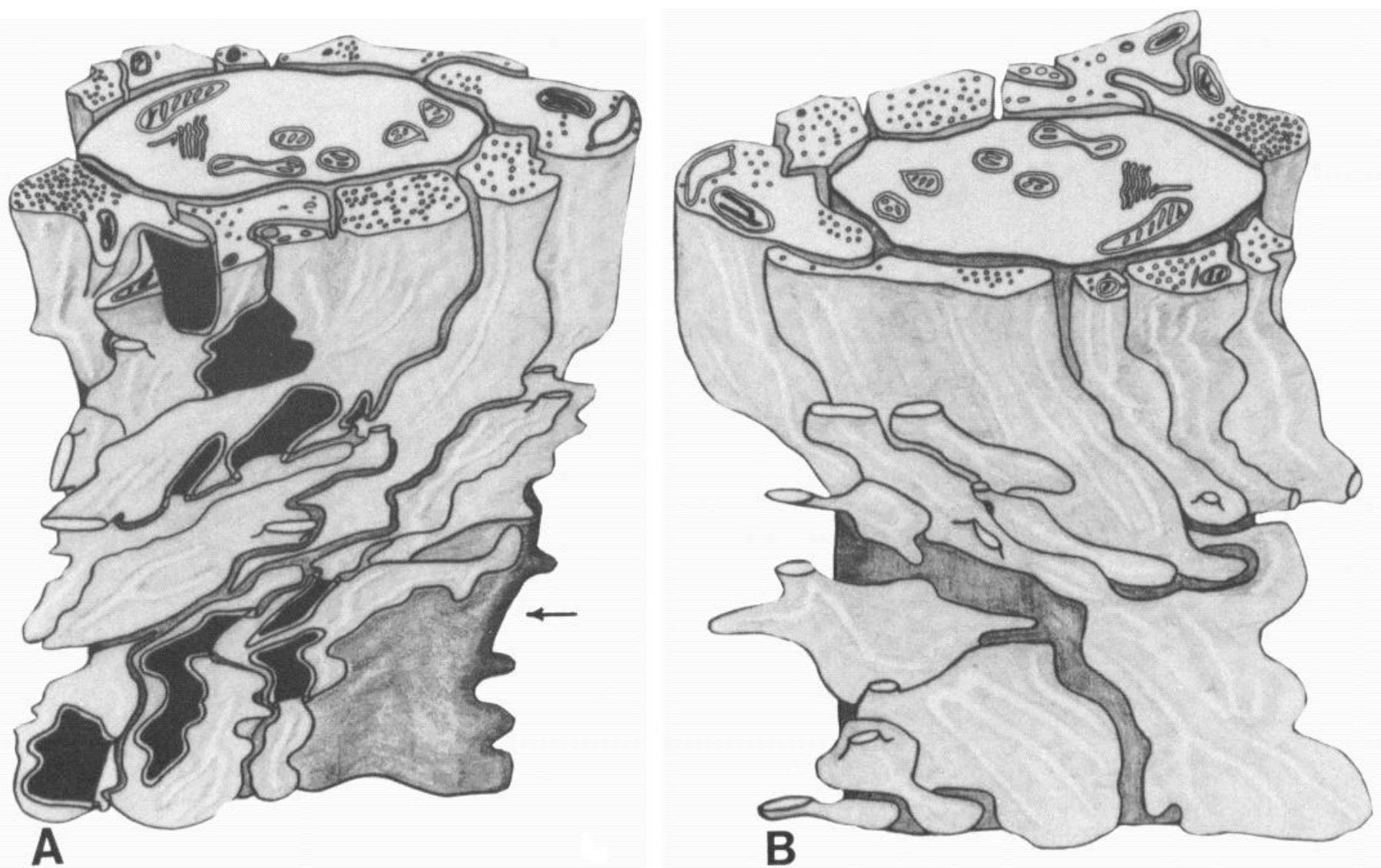

Figure 2. Drawing of a graphical three-dimensional reconstruction of a $5-\mu \mathrm{m}$ length of the dendrite. $A$, The side of the dendrite facing away from the parent cell body bore PSIs and broad nerve terminal processes caught in a fold of a neighboring terminal. These are depicted in black. $B$, The other side of the same dendrite showed no PSIs or folds. 


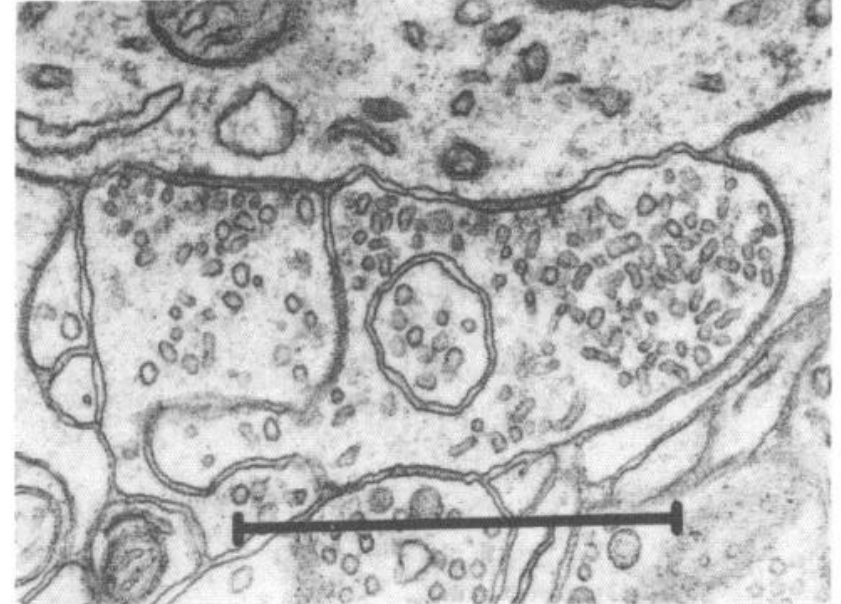

Figure 3. A section from the reconstruction in Figure 2 which clearly shows the origin of the PSI from the right terminal as well as a cross-sectioned PSI within the right terminal. This pair of terminals occurred at the level indicated by the arrow in Figure $2 A$. Scale bar, $1 \mu \mathrm{m}$.

the dendritic spines frequently elaborate a pseudopodium-like structure which has been called a spinule (Westrum and Blackstad, 1962). Spinules which occur within the boundary of the postsynaptic density at the active zone of the synapse have been termed synaptic spinules (Tarrant and Routtenberg, 1977). Both of these forms demonstrate a complex course of dendritic spine and axonal membrane apposition. Pseudopodia originating from nerve terminals appeared to be absent from the bulk of this neuropil. However, at the base of the apical dendrites of the pyramidal neurons is a relatively spinefree region where abutted terminals form dendritic shaft synapses. Occasionally small PSIs were encountered in this region. In the $\mathrm{CA}_{4}$, hilar region, large nerve terminals which could be seen to make asymmetrical synapses with dendritic spines were found to contain PSIs. A crosssectioned example is shown in Figure 4.

Nucleus accumbens. This region was examined just inferior to the most rostral extension of the lateral ventricles. The neuropil was characterized by the presence of spiny dendrites articulating with small and large nerve terminals. The nerve terminals were packed densely with vesicles and the dendritic spines showed spine apparati and frequent, but short, spinules. No nerve terminal pseudopodia were encountered in this nucleus.

Globus pallidus. In the amygdala and hippocampus, after a persistent search, one can locate cases in which nerve terminals are interdigitated. In contrast, such relationships are readily encountered in the globus pallidus. The dendrites are typically smooth and are covered with a mosaic of directly abutted nerve terminals making symmetrical axodendritic synapses. Many of these are in various stages of interdigitation (the micrographs of Fox et al., 1974, provide excellent illustrations). PSIs also were seen in nerve terminals which were not in contact with dendrites in the section examined. Apart from simple longitudinal and cross-sections, PSIs also were observed surrounded by four-unit membranes. In the stimulated ray electric organ, it has been shown that this can arise when a pseudopodium extending in one direction curls against a pseudopodium coming from the opposite

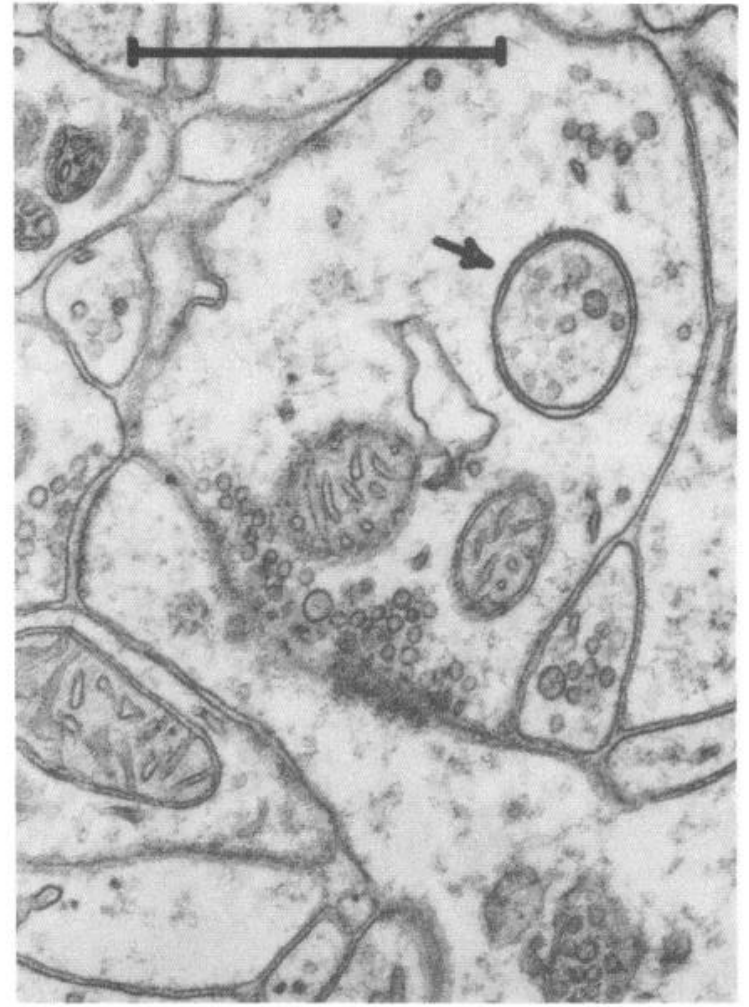

Figure 4. Hilar region of the dentate gyrus of the hippocampus. A cross-sectioned PSI (arrow) is present in the large nerve terminal synapsing with the dendritic spine. Note the similar size but different contents of the cross-sectioned mitochondria in the same terminal. Scale bar, $1 \mu \mathrm{m}$.

direction (see Fig. 1). Apparent longitudinal sections are shown in Figures 5 and 6 in which initial and late stages of a compound, curling relationship are seen.

It may be noted that this interaction involves constriction of the PSI base. Such constrictions were also evident in single PSIs in both the globus pallidus and substantia nigra.

Substantia nigra. Many authors have noted the similarity between the neuropil of the globus pallidus and the pars reticulata of the substantia nigra. This similarity extends to the PSI population which displays a similar spectrum of configurations in both locations.

Caudate. The caudate neuropil presents an abundance of spiny dendrites; the associated nerve terminals bear frequent shallow spinules. Where cross-sections of dendrites bearing nerve terminals are observed, there is less likelihood of terminal abutment than is the case in the globus pallidus and substantia nigra. Nevertheless, occasional PSIs were encountered in small nerve terminals synapsing with dendritic spines. The simultaneous presence of PSIs and spinules within the caudate permitted the determination of whether they could occur in the same nerve terminal. One such case was found.

\section{Discussion}

\section{Distribution of nerve terminal pseudopodia}

We have demonstrated the widespread presence in the mammalian CNS of a nerve terminal inter-relationship which is known to result from repetitive stimulation of the electric organ in Narcine brasiliensis (Boyne et al., 

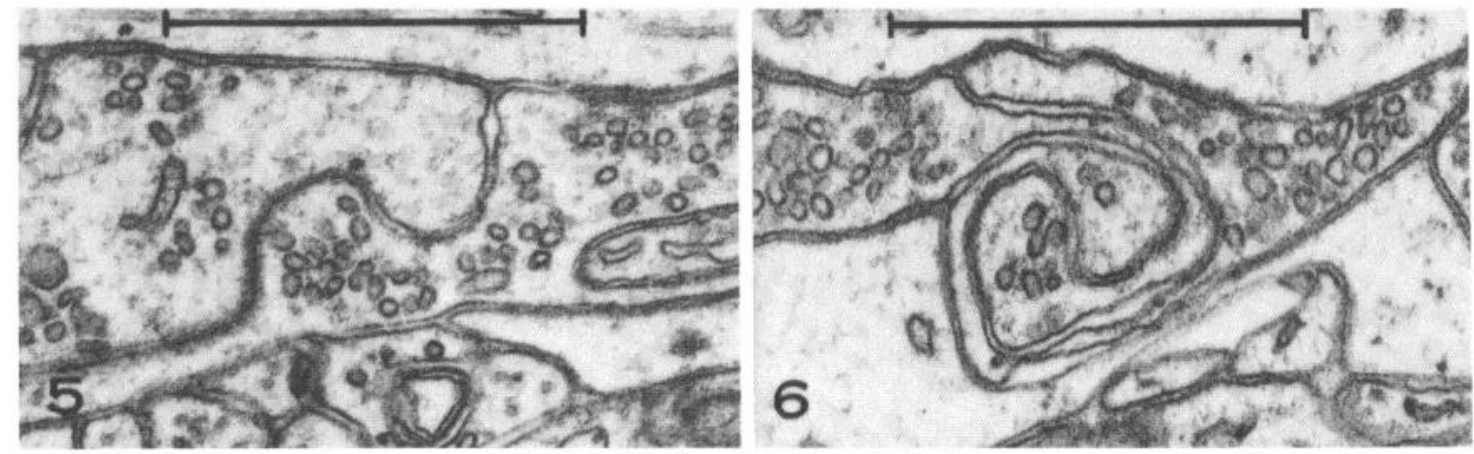

Figures 5 and 6. Globus pallidus. Simple (Fig. 5) and complex (Fig. 6) wrapping of compound PSIs are illustrated. Scale bars, $1 \mu \mathrm{m}$.

1975; Boyne and McLeod, 1979). The observations were made in rats which had not been subjected to deliberate experimental stimulation.

There appeared to be a possibility that PSIs may have arisen in susceptible terminals during seizures triggered by the aldehyde perfusion. However, the use of deep urethane anesthesia and $5 \mathrm{~mm}$ cobalt chloride has permitted us to eliminate the limb movements which may indicate seizures in barbiturate-anesthetized rats, and this has not eliminated the presence of PSIs.

The possibility that these are chemical fixation artifacts also must be considered. PSIs were identified originally in matched pairs of stimulated and control electric organ slices which were fixed by immersion; they were encountered 20 times more frequently in stimulated tissues (Boyne et al., 1975). That evidence suggested that they are a consequence of stimulation rather than aldehyde fixation. Furthermore, they are found most readily in the best preserved brains that we have prepared; possible confusions between cross-sectioned PSIs and mitochondria are minimal in a well fixed brain.

The results suggest that these structures occur in vivo. Our survey of six brain nuclei further suggests that PSIs are most likely in regions with smooth dendrites when they bear abutted boutons forming symmetrical synapses. This is the situation in the amygdala (central nucleus), globus pallidus, and substantia nigra. In contrast, boutons in nuclei with spiny dendrites are more likely to form asymmetrical synapses and to be invaded by dendritic spinules. Invasion of a nerve terminal by nerve terminals is then infrequent. Nucleus accumbens and the bulk of the hippocampal neuropil fall into this category. Large nerve terminals in the hilus and small terminals in the caudate appear to be exceptional in that they form asymmetrical synapses with dendritic spines and they also can bear PSIs.

There is a similarity between PSI and flask-shaped interdigitations between smooth muscle cells (Dewey and Barr, 1964). In the latter case, the apposed membranes are frequently sites of gap junction formation (Revel et al., 1967; Uehara and Burnstock, 1970). No such specializations have been observed in nerve terminal PSIs.

\section{Physiological significance of pseudopodial indentations}

As membrane stores. It seems likely that PSIs represent a mechanism for accommodating excess plasma membrane without compromising the adjacent synaptic relationships. The advantage of this can be recognized by considering a simple system in which it does not occur. Pysh and Wiley (1974) stimulated preganglionic nerve terminals synapsing with small dendrites in the cat superior cervical ganglion. The terminal membrane growth led to a "grasping" movement around the dendritic crosssection, lifting glial elements away in the process. If this were to occur in the globus pallidus or substantia nigra, abutted nerve terminals might engage in a wrestling match for a synaptic position on a dendrite. In some circumstances, this might be a useful form of plasticity, but when PSIs can form, synaptic derangement should be minimized.

As diffusion traps. Interdigitations which may have been necessitated as a form of membrane storage appear to be inevitable diffusion traps. When the space around an excitable membrane is restricted by adjacent membranes, there is a possibility for solutes released during an action potential to reach significant concentrations in the narrow extracellular space. Furthermore, as shown by Frankenhaeuser and Hodgkin (1956) with the squid giant axon, there is then an opportunity for progressive accumulations (e.g., of potassium) with repetitive firing if the quantity released per impulse is not dissipated during the interstimulus interval. Assuming that nerve terminals carry action potentials (Katz and Miledi, 1965), PSIs may be expected to accumulate potassium because (i) both participating membranes are excitable and 1.0 pmol cm$~^{-2}$ of potassium is released per action potential (Keynes and Ritchie, 1965) and (ii) diffusional potassium dissipation would be restricted to the one end which is open to the general extracellular space. Calculations of the theoretical active and passive potassium release (Keynes and Ritchie, 1965; Ritchie and Straub, 1975, respectively), potassium re-uptake (Cohen and DeWeer, 1975), and linear diffusion assuming the free solution diffusion coefficient (Crank, 1975) suggest that the tip of a 2- $\mu$ m-long PSI would have a potassium concentration of 5 to $6 \mathrm{~mm}$ when firing at $250 \mathrm{~Hz}$. The neuronal membrane has been noted to be relatively insensitive to external potassium in this concentration range (Somjen, 1979). Therefore, it seems unlikely that PSIs of the size seen in the amygdala could be fired rapidly enough to accumulate physiologically significant potassium concentrations. However, recent measurements have shown that the potassium concentration in the space around an ion-sensitive microelectrode in the CNS can be readily brought to $12 \mathrm{~mm}$ (e.g., with $10 \mathrm{~Hz}$ stimulation of the fiber tracts projecting into the measured region; Krnjevic 
et al., 1980; Nicoll, 1979; Nicholson, 1980). Since local PSI accumulations will add to whatever accumulation has gone on in the space around them, then the highest concentrations may be expected in the tips of these structures. The tip concentrations then would be dependent on PSI size and shape and would be in the range which influences neuronal membrane potentials. We are therefore led to suggest that, if the activity-linked potassium accumulations which have been measured in brain tissue (Orkand et al., 1966; Krnjevic and Morris, 1974; Richter et al., 1978; Nicoll, 1979; Krnjevic et al., 1980) can modulate information transfer, then the unmeasured additional accumulations within PSIs may, like the tip of a pencil, exert a profound influence on the function of a system of which they are a small part.

Diffusion coefficients for amino acids are about $45 \%$ of that for potassium (in free solution). Diffusion of nucleotides may be expected to be still slower. Nonsynaptic release of these solutes may be much less than that for potassium, but receptors may be sensitive in the nanomole to micromole range. (The threshold sensitivity to GABA in desheathed ganglia is $1 \mu \mathrm{m}$; Adams and Brown, 1975.) Consequently, PSIs could be accumulation sites of automodulating substances, the effects of which may combine with those of release potassium. Shefner and Levy (1980) recently have described interactions between amino acid- and potassium-induced depolarization in primary afferents of the bullfrog spinal cord. That paper and the review by Levy (1980) provide detailed discussions of the potential interactions.

\section{References}

Abood, L. G., K. Koketsu, and S. Miyamoto (1962) Outflow of various phosphates during membrane depolarization of excitable tissues. Am. J. Physiol. 202: 469-474.

Adams, P. R., and D. A. Brown (1975) Actions of $\gamma$-aminobutyric acid on sympathetic ganglion cells. J. Physiol. (Lond.) 250: 85-120.

Birks, R. I. (1974) The relationship of transmitter release and storage to fine structure in a sympathetic ganglion. J. Neurocytol. 3: 133-160.

Boyne, A. F., and S. McLeod (1979) Ultrastructural plasticity in stimulated nerve terminals: Pseudopodial invasions of abutted terminals in Torpedine ray electric organ. Neuroscience 4: 615-624.

Boyne, A. F., and S. B. Tarrant (1979) Pseudopodial invasions of nerve terminals in rat amygdala. Soc. Neurosci. Abstr. 5: 425.

Boyne, A. F., T. P. Bohan, and T. H. Williams (1975) Changes in cholinergic synaptic vesicle populations and the ultrastructure of nerve terminal membranes of Narcine brasiliensis electric organ stimulated to fatigue in vivo. J. Cell Biol. 67: 814-825.

Ceccarelli, B., W. B. Hurlbut, and A. Mauro (1973) Turnover of transmitter and synaptic vesicles at the frog neuromuscular junction. J. Cell Biol. 57: 499-524.

Chang, F. -L., M. K. Floeter, and W. T. Greenough (1979) Application of high magnesium concentration perfusionfixation to rat visual cortex. Soc. Neurosci. Abstr. 5: 426.

Cohen, L. B., and P. DeWeer (1975) Structural and metabolic processes directly related to action potential propagation. In Handbook of Physiology. Section 1: The Nervous System, Vol. 1, Part 1, Cellular Biology of Neurons, J. M. Brookhart, V. B. Mountcastle, E. R. Kandel, and S. R. Geiger, eds., pp. 137-159, American Physiological Society, Bethesda, MD.
Crank, J. (1975) The diffusion coefficient is constant. In The Mathematics of Diffusion, J. Crank, ed., Ed. 2, pp. 12-16, Clarendon, Oxford.

Dewey, M. M., and L. Barr (1964) A study of the structure and distribution of the nexus. J. Cell Biol. 23: 553-585.

DiFiglia, M., T. Pasik, and P. Pasik (1979) Ultrastructure of the monkey globus pallidus. Soc. Neurosci. Abstr. 5: 70.

Fox, C. A., A. N. Andrade, I. J. Lu Qui, and J. A. Rafols (1974) The primate globus pallidus: A Golgi and electron microscopic study. J. Hirnforsch. 15: 75-194.

Frankenhaeuser, B., and A. L. Hodgkin (1956) The after-effects of impulses in the giant nerve fibers of Loligo. J. Physiol. (Lond.) 131: 341-376.

Hall, E. (1968) Some observations on the ultrastructure of the amygdala. Zellforch. Mikrosk. Anat. 92: 169-185.

Heuser, J. E., and T. S. Reese (1973) Evidence for recycling of synaptic vesicle membrane during transmitter release at the frog neuromuscular junction. J. Cell Biol. 57: 315-344.

Karnovsky, M. J. (1965) A formaldehyde-glutaraldehyde fixative of high osmolarity for use in electron microscopy. J. Cell Biol. 27: 137A-138A.

Karnovsky, M. J. (1971) Ise of ferrocyanide-reduced osmium tetroxide in electron microscopy. In Eleventh Annual Meeting of the American Society for Cell Biology, New Orleans, p. 146, Rockefeller, New York.

Katz, B., and R. Miledi (1965) Propagation of electric activity in motor nerve terminals. Proc. R. Soc. Lond. (Biol.) 161: 453-482.

Kershaw, P., and B. N. Christensen (1980) A quantitative analysis of ultrastructural changes induced by electrical stimulation of identified spinal axons in the larval lamprey. J. Neurocytol. 9: 119-138.

Keynes, R. D., and J. M. Ritchie (1965) The movements of labelled ions in mammalian non-myelinated nerve fibers. $\mathrm{J}$. Physiol. (Lond.) 179: 333-367.

Konig, J. F. R., and R. A. Klippel (1970) The Rat Brain: A Stereotaxic Atlas, Krieger, Huntington, NY.

Krnjevic, K., and M. E. Morris (1974) Extracellular potassium accumulation evoked by activity of primary afferent fibers in cuneate nucleus and dorsal horn of cats. Can. J. Physiol. Pharmacol. 52: 852-871.

Krnjevic, K., M. E. Morris, and R. J. Reiffenstein (1980) Changes in extracellular $\mathrm{Ca}^{++}$and $\mathrm{K}^{+}$activity accompanying hippocampal discharges. Can. J. Physiol. Pharmacol. 58: 579583.

Levy, R. A. (1980) Presynaptic control of input to the central nervous system. Can. J. Physiol. Pharmacol. 58: 751-766.

Model, P. G., S. M. Highstein, and M. V. L. Bennett (1975) Depletion of vesicles and fatigue of transmission at a vertebrate central synapse. Brain Res. 98: 209-228.

Nicholson, C. (1980) Dynamics of the brain cell microenvironment. Neurosci. Res. Program Bull. 18: 275-284.

Nicoll, R. A. (1979) Dorsal root potentials and changes in extracellular potassium in the spinal cord of the frog. $\mathrm{J}$. Physiol. (Lond.) 290: 113-127.

Orkand, R. K. (1980) Extracellular potassium accumulation in the nervous system. Fed. Proc. 39: 1515-1518.

Orkand, R. K., J. G. Nicholls, and S. W. Kuffler (1966) Effect of nerve impulses on the membrane potential of glial cells in the central nervous system of amphibia. J. Neurophysiol. 29: 788-806.

Pysh, J. J., and R. G. Wiley (1974) Synaptic vesicle depletion and recovery in cat sympathetic ganglia electrically stimulated in vivo. Evidence for transmitter release by exocytosis. J. Cell Biol. 60: 365-374.

Revel, J. P., W. Olson, and M. J. Karnovsky (1967) A twentyangstrom gap junction with a hexagonal array of subunits in smooth muscle. J. Cell Biol. 35: 112A. 
Richter, D. W., H. Camerer, and U. Sonnhof (1978) Changes in extracellular potassium during the spontaneous activity of medullary respiratory neurones. Pfluegers Arch. 376: 139149 .

Ritchie, J. M., and R. W. Straub (1975) The movement of potassium ions during electrical activity and the kinetics of the recovery process in the non-myelinated fibers of the garfish olfactory nerve. J. Physiol. (Lond.) 249: 327-348.

Schaeffer, S. F., and E. Raviola (1978) Membrane recycling in the cone cell endings of the turtle retina. J. Cell Biol. 79: 802825 .

Shefner, S., and R. Levy (1980) Interaction between amino acid-induced and $\mathrm{K}$-induced depolarization of primary afferents in the bullfrog spinal cord. Can. J. Physiol. Pharmacol. 58: 1286-1294.

Somjen, G. G. (1979) Extracellular potassium in the mammalian central nervous system. Annu. Rev. Physiol. 41: 159-177.

Tarrant, S. B., and A. Routtenberg (1977) The synaptic spinule in the dendritic spine: Electron microscopic study of the hippocampal dentate gyrus. Tissue Cell 9: 461-473.

Uehara, Y., and G. Burnstock (1970) Demonstration of 'gap junctions' between smooth muscle cells. J. Cell Biol. 44: 215217.

Weinreich, D., and R. Hammerschlag (1975) Nerve impulseenhanced release of amino acids from nonsynaptic regions of peripheral and central nerve trunks of bullfrog. Brain Res. 84: $137-142$.

Westrum, L. E., and T. W. Blackstad (1962) An electron microscopic study of the stratum radiatum of the rat hippocampus (regio superior, CA1) with particular emphasis on synaptology. J. Comp. Neurol. 119: 281-309.

Zimmermann, H., and V. P. Whittaker (1974) Effect of electrical stimulation on the yield and composition of synaptic vesicles from the cholinergic synapses of the electric organ of Torpedo: A combined biochemical, electrophysiological and morphological study. J. Neurochem. 22: 435-450. 